\title{
IMPACT OF TRAFFIC LOAD RANDOMNESS ON FATIGUE OF STEEL BRIDGES
}

\author{
ADAM WYSOKOWSKI \\ Road, Bridges and Railway Department, Faculty of Building, Architecture \\ and Environmental Engineering, \\ University of Zielona Góra, Zielona Góra, Poland
}

Received 12 February 2020; accepted 13 July 2020

\begin{abstract}
The article considers the influence of the randomness of traffic load on the fatigue of elements of steel bridge structures. The phenomenon occurs specifically in the case of bridges characterized by significant width, with many traffic lanes and a high vehicle velocity, especially in the case of heavy goods vehicles. It has been shown that underestimation of operational durability, including fatigue durability, can be up to $23 \%$. Operational loads increase due to the overlapping of traffic loads, which leads to the increased fatigue of elements of steel bridge structures. In an effort to assess this influence and its value, elements of the problem of the randomness of road traffic loads were compiled and described, and a simulative analysis of the operational strength of various lengths (spans) of the main girders of bridges was carried out. The analyses showed that for the structures with spans length of up to $10.0 \mathrm{~m}$, the influence of passing vehicles could be skipped in calculations, especially in the case of weak traffic.
\end{abstract}

Keywords: durability, fatigue, safety, steel bridges, traffic load randomness.

\footnotetext{
* Corresponding author. E-mail: awysokowski@infra-kom.eu

Adam WYSOKOWSKI (ORCID ID 0000-0002-4547-2453)

Copyright (C) 2020 The Author(s). Published by RTU Press

This is an Open Access article distributed under the terms of the Creative Commons Attribution License (http://creativecommons.org/licenses/by/4.0/), which permits unrestricted use,

distribution, and reproduction in any medium, provided the original author and source are credited.
} 


\section{Introduction}

The influence of operational loads from heavy goods vehicles on the bearing capacity and fatigue capacity of steel bridge structures is relatively well understood regarding the impact of cyclically variable loads, it has been described in many publications, e.g. (Guo, Frangopol, \& Chen, 2012; Kwon, \& Frangopol, 2010; Wysokowski, 2001, 2018; Zhang, Wu, \& Zhu, 2017). Fatigue tests of structural elements are carried out mainly using a cyclic model load, disregarding randomness of their amplitude. In the assessment of the operational durability of road bridges, the problem of the high randomness of loads from road traffic appears, which has not been completely recognized in practice. It is especially important when analysing road bridges with relatively high traffic densities or of large width, comprising many traffic lanes. Thus, assuming vehicle traffic on the bridge as a deterministic model may lead to certain errors when assessing the operational strength of elements of steel bridge structures.

Current research assesses the influence of the simultaneous moving of vehicles over a bridge as the overlapping of loads when calculating the operational strength parameters for road bridges. The study presents the results of original long-term research on steel bridge fatigue durability and the influence of the value of traffic loads on the operational strength of a bridge structure.

\section{Randomness of vehicle traffic on road bridges}

The road traffic randomness pertains not only to the types of vehicles (their loads, number of axles, total length, axle spacing), but also to the manner in which they move across a bridge (O'Brien, \& Enright, 2011). When describing traffic on road bridges, the following aspects can be considered significant (Croce, 2019, 2020; Liu, Xiao, Lu, \& Deng, 2016; Song, \& Ding, 2013; Wenzel, \& Veit-Egerer, 2009; Yan, Deng, \& He, 2016):

- non-axiality of vehicle movement across the width of a traffic lane - it affects the amount of load acting on individual bridge structural elements depending on their location on the width of a bridge structure;

- division of traffic volume into individual traffic lanes on the horizontal cross-section of a bridge (at given daily traffic volumes), this division has an impact on the magnitude of the loads of individual bridge structural elements depending on their location under the roadway structure in a bridge crosssection; 
- speed of vehicles - speed of vehicles on the bridge affects the likelihood of simultaneous passage of vehicles over the bridge structure. Thus, it has a considerable impact on the magnitude of loads on the bridge structure elements, mainly the main girders;

- distances between the vehicles - they affect the value and frequency of loads. The greater the distance, the smaller the load on the analysed structural element;

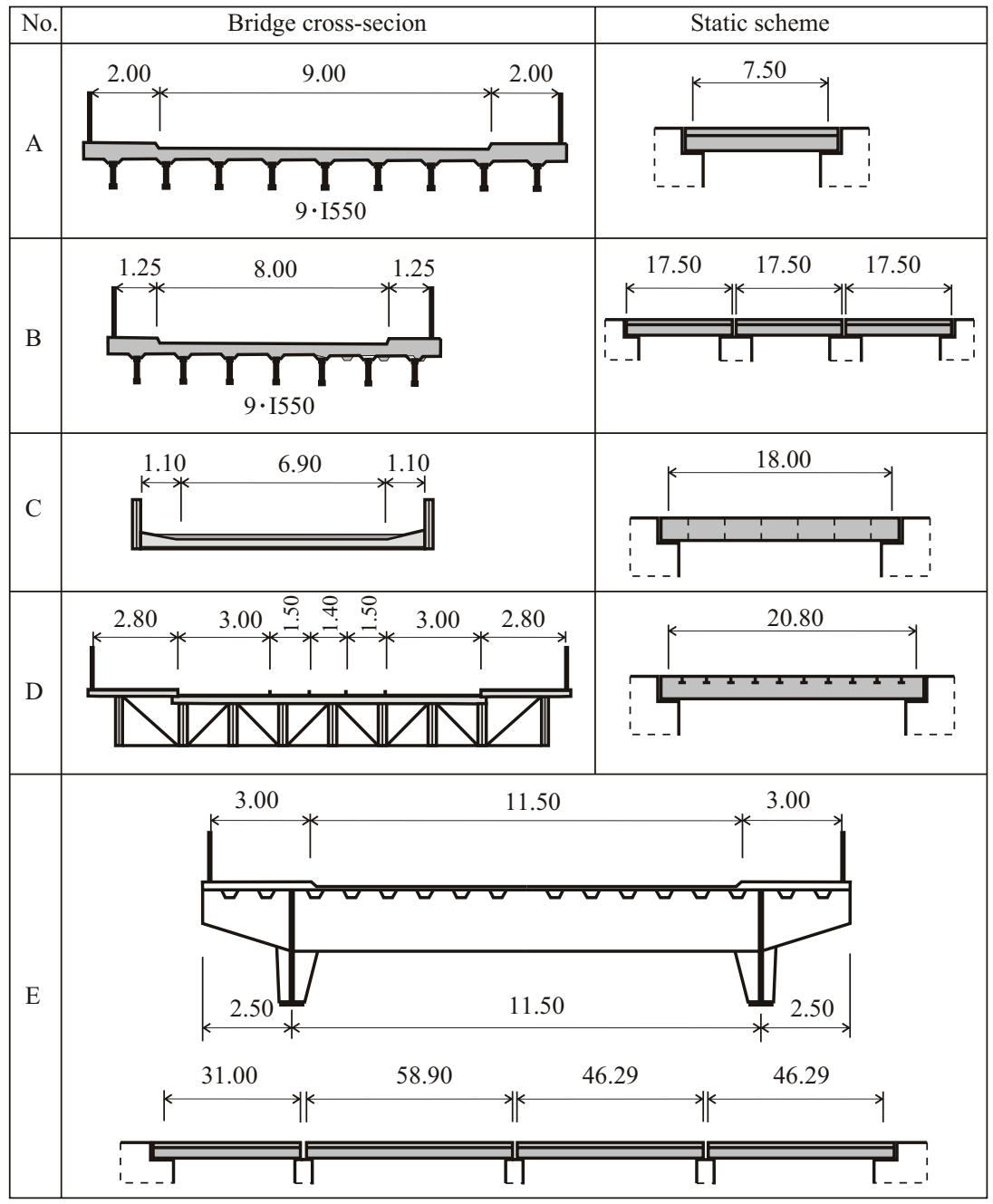

Figure 1. Static schemes of bridge structures that were tested within the research on the randomness of road traffic, $m$ 
- overtaking of vehicles on the bridge deck - when vehicles overtake each other, the load on e.g. the main girders will be much higher.

In order to determine the influence of simultaneous moving of vehicles over a bridge considering the above-mentioned issues and parameters, exploratory research of five different types of bridges has been conducted:

- Bridge A - single span composite structure, three traffic lanes, length $l=7.50 \mathrm{~m}$, located in Łagiewniki;

- Bridge B - three-span composite structure, two traffic lanes, total length $l=52.50 \mathrm{~m}$, located in Dobromierz;

- Bridge $\mathrm{C}$ - single span steel structure, two traffic lanes, length $l=18.00 \mathrm{~m}$, located in Korzeńsko;

- Bridge D - single span steel structure, three traffic lanes, length $l=21.00 \mathrm{~m}$, located in Wrocław (over the Odra River);

- Bridge E - four-span steel structure, three traffic lanes, total length $l=182.00 \mathrm{~m}$, located in Opole (over the Odra River).

The static schemes of these bridge structures are summarized in Figure 1.

\subsection{Non-axiality of vehicle movement on the width of a traffic lane}

Based on the previously conducted studies (Bruls, 1980; Pfeifer, 1982), it can be stated that the axis of moving vehicles does not coincide with the axis of the traffic lane.

Figure 2 shows the results of measurements of the frequency, at which tyre tracks from the moving vehicles appear across the width of a traffic lane for bridges. Based on the presented results of measurements, it can be stated that the average location of the axis of moving vehicles is shifted to the right (closer to the centre of the bridge) in relation to the axis of the traffic lane.

The value of this shift depends on the type of moving heavy goods vehicles. In Figure 2, it can be noticed that light, two-axle vehicles most often move closer to the central edge of the traffic lane, whereas heavy vehicles (with trailers, tractor units) move closer to the outer edge of the traffic lane.

The amount of shift in the passing path of vehicles in relation to the traffic lane axis also depends on the type of road. Based on the studies, it can be observed that for single carriageway roads, the value of the discussed shift is merely $0.065 \mathrm{~m}$, whereas for two-carriageway roads, the asymmetry of movement in relation to the lane axis is greater (vehicles moving closer to the centre of the road), it amounts to $0.155 \mathrm{~m}$. 


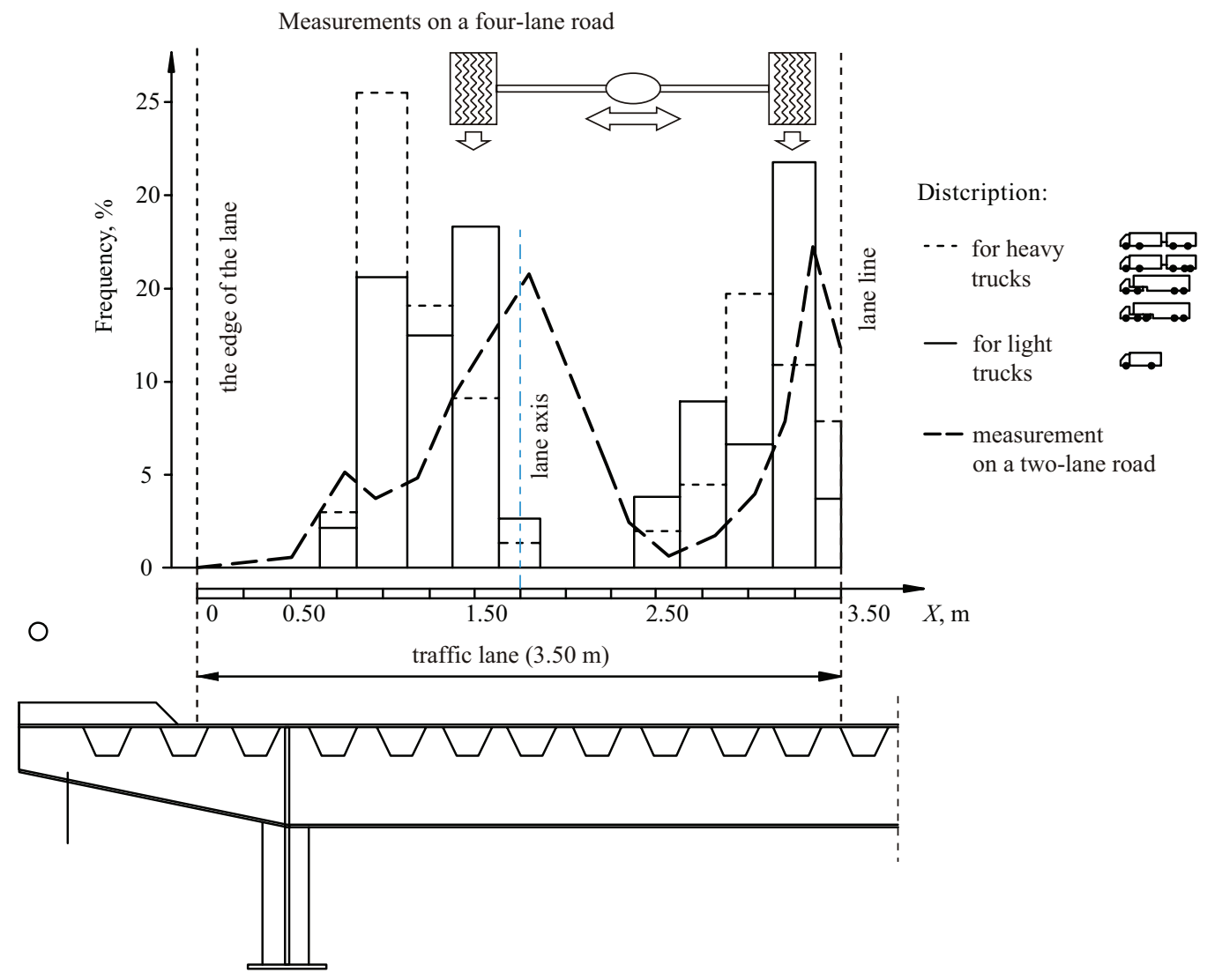

Figure 2. Frequency of appearance of tyre tracks across the width of a traffic lane (Bruls, 1980)

The observations of road traffic over the course of own studies on five bridges (A-E) prove that in every case the vehicles moved along the lanes closer to the central edge, and the values of the asymmetry of movement were, on average, from $0.60 \mathrm{~m}$ for a single carriageway wide bridge A ( $2 \mathrm{~m} \times 4.50 \mathrm{~m})$ and $0.45 \mathrm{~m}$ for a dual carriageway, three-lane one-way bridge $\mathrm{E}$, to $0.15 \mathrm{~m}$ for a single carriageway Bridge $\mathrm{C}$ with traffic lane width of $2 \mathrm{~m} \times 3.45 \mathrm{~m}$.

As confirmed in the research conducted by Jacquemoud (1980), the horizontal distribution of the vehicle movement on a traffic lane can be described by a normal distribution. Thus, the value of the coefficient of the lateral distribution of loads in the case of the analysed girder will also be characterized by a normal distribution (Schilling, 1982). 
Keeping in mind the small values of asymmetry in relation to traffic lane width, in general applications it is possible to assume that vehicles move along a single track and their horizontal axis coincides with the traffic lane axis.

\subsection{Division of vehicles into individual traffic lanes}

In the case of multi-lane bridges (of more than two traffic lanes), the problem of traffic velocity distribution on individual lanes of the road cross-section should be addressed. This distribution depends on the traffic volume, the type of road, its longitudinal slope, the structure of traffic and its organization. Individual differences between particular countries caused by specific behaviours of the drivers also occur in this respect.

Analysing the results of own measurements of traffic volume on the individual lanes of multi-lane Bridge $\mathrm{E}$ (with three traffic lanes) presented in Figure 3, it can be confirmed that from the obtained general traffic volume of heavy good vehicles amounting to 2976 units per day, their highest number, i.e. $60.2 \%$, move down the centre lane, fewer $24.2 \%$ - down the acceleration lane, and merely $15.6 \%$ - down the overtaking lane. The last one, however, was used by the highest number of unloaded (empty) vehicles. Moreover, it should be mentioned that some of the vehicles changed lanes while crossing the bridge. Also, on

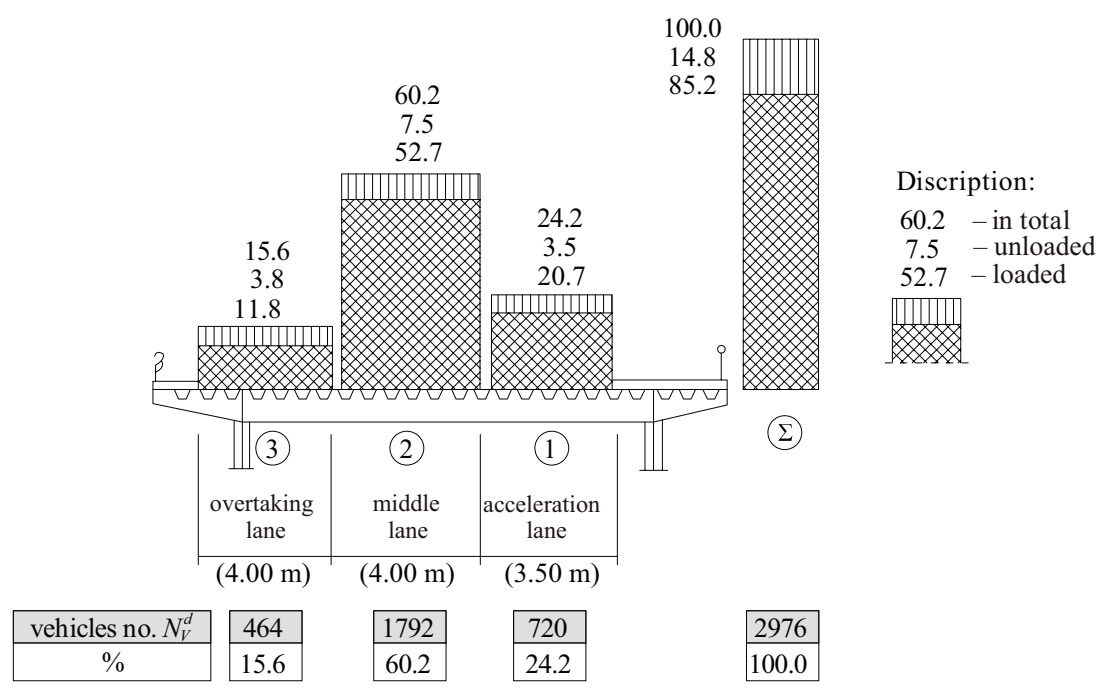

Figure 3. Frequencies of occurrence of heavy goods vehicles in percent on individual traffic lanes of a six-lane bridge 
the analysed road section of Bridge E, the leftmost lane (overtaking lane) on Fatigue of Steel also allowed heavy vehicles to overtake other vehicles.

Figure 4 presents histograms of the total weights of vehicles registered on the individual traffic lanes over the course of field tests for Bridge E. The same picture also provides information regarding the volume of vehicles for a given lane $N_{V}^{d}$ in the course of a day, the weights of the vehicles $Q_{a v}$ and the total load $\Sigma Q$ per day for individual traffic lanes.

With regard to the load of individual traffic lanes, histograms in Figure 4 show that heavy vehicles with a gross weight of over $300 \mathrm{kN}$ most often move along the centre lane No. 2, while relatively light vehicles with a gross weight of under $140 \mathrm{kN}$ move along the overtaking lane.

Figure 5 presents relationships of the percentage of the type of road traffic on individual traffic lanes in the case of a four-lane (Figure 5a) and six-lane road (Figure 5b) depending on the traffic volume per hour. These relationships were given for two types of traffic: heavy traffic (less than $25 \%$ of light vehicles in the total traffic) and light traffic (between $25-50 \%$ of light vehicles).

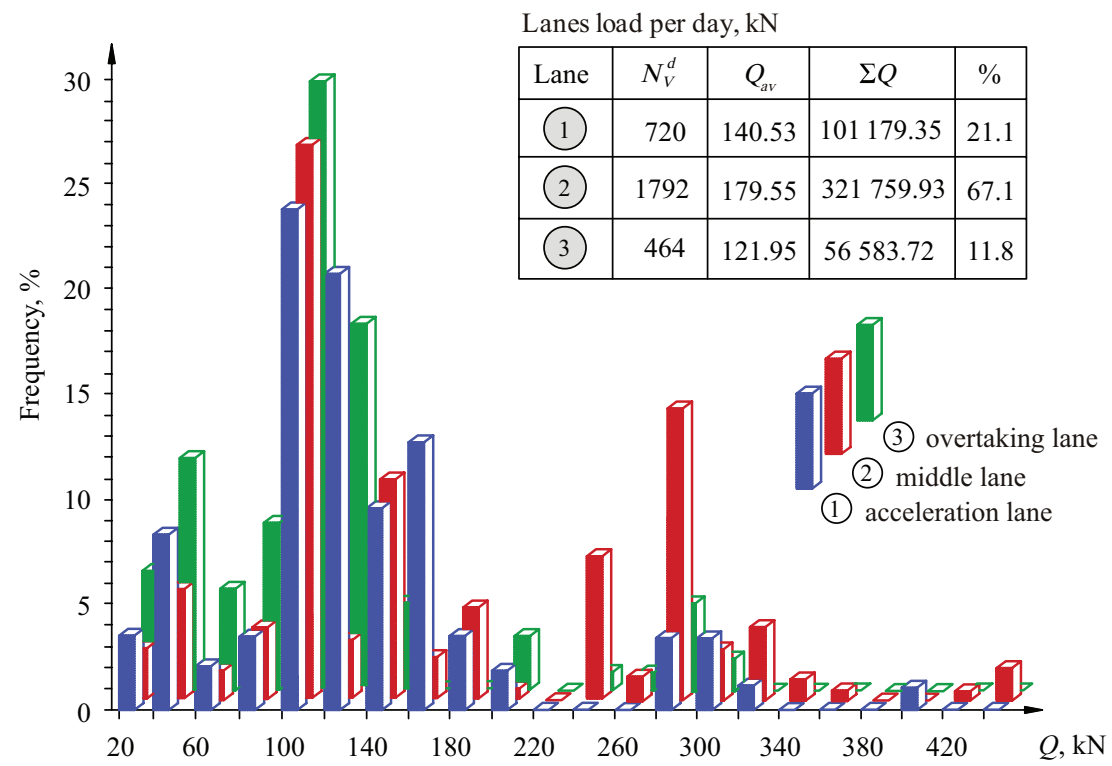

\begin{tabular}{|c|c|c|c|c|c|c|c|c|c|c|c|c|c|c|c|c|c|c|c|c|c|c|c|}
\hline \multirow{2}{*}{} & 1 & 3.3 & 8.3 & 2.1 & 3.3 & 24.4 & 21.1 & 9.9 & 13.2 & 3.3 & 2.1 & - & - & - & 3.3 & 3.3 & 1.2 & - & - & - & 1.2 & - & - \\
\cline { 2 - 13 } & 2 & 2.3 & 6.0 & 1.8 & 4.0 & 27.2 & 3.7 & 11.6 & 4.0 & 5.0 & 0.5 & - & 7.5 & 1.3 & 14.8 & 2.7 & 3.5 & 1.3 & 0.5 & - & - & 0.5 & 1.8 \\
\cline { 2 - 13 } & 3 & 5.1 & 12.2 & 5.1 & 9.0 & 30.8 & 18.6 & 5.1 & - & - & 3.2 & - & 1.9 & 1.9 & 5.1 & 2.0 & - & - & - & - & - & - & - \\
\hline
\end{tabular}

Figure 4. Histograms of total weights of vehicles for individual traffic lanes 
a)

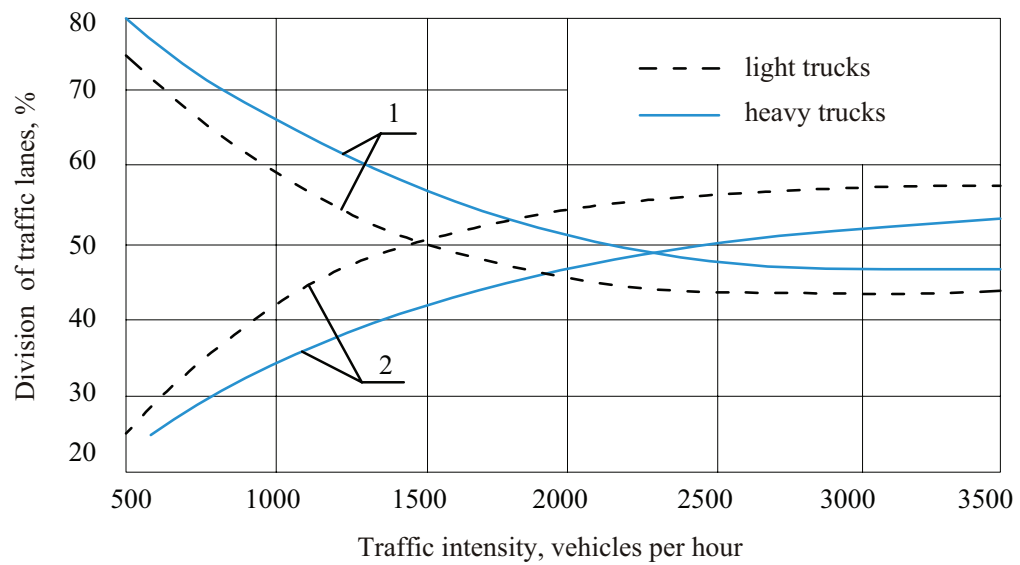

b)

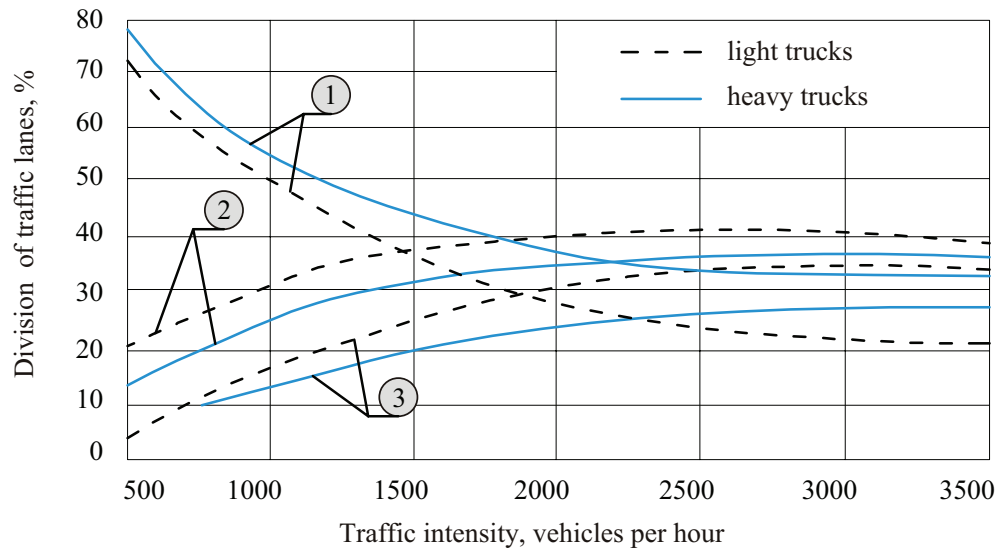

Figure 5. Percentage breakdown of traffic into lanes a) for a four-lane road: 1 - outer lane, 2 - centre lane, b) for six-lane road: 1 - outer lane, 2 - intermediate lane, 3 - centre lane

In order to use the relationships given in Figure 5 for operational strength analyses applying Lagrange's interpolation formula, the function of the share of model vehicles on individual traffic lanes of a four-lane bridge, depending on the traffic volume of heavy goods vehicles $N_{V}^{d}$ per day (in the entire bridge cross-section) was introduced.

The maximum practical calculation capacity of model vehicles for a bridge with four lanes in both directions is also used in order to develop this algorithm. For this purpose, the calculated capacity values are used, considering the conversion factors for the type of model vehicles in accordance with the Eq. (1):

$$
N_{p, \max }=\frac{\eta}{\left[a_{1} U_{1}+\left(a_{2}+a_{3}\right) U_{2}\right] \eta+1} N_{p, u, \max / h} \cdot 16 h,
$$


where $a_{1}, a_{2}, a_{3}$ - relative frequency of occurrence of model vehicles; $\eta$ on Fatigue of Steel relative frequency of heavy goods vehicles; $U_{1}, U_{2}$ - conversion factors for model vehicles.

For the outer (slow) lane $w$, it takes the form of:

$$
\begin{gathered}
y_{1}\left(N_{V}^{d}\right)=0.5 N_{V}^{d}\left(-3.9657 \cdot 10^{-13} N_{V}^{d 3}+1.3253 \cdot 10^{-8} N_{V}^{d 2}\right. \\
\left.-1.4617 \cdot 10^{-4} N_{V}^{d}+1.000146\right)
\end{gathered}
$$

whereas for the centre lane 2, it has the form of:

$$
\begin{gathered}
y_{2}\left(N_{V}^{d}\right)=0.5 N_{V}^{d}\left[1-\left(-3.9657 \cdot 10^{-13} N_{V}^{d 3}+1.3253 \cdot 10^{-8} N_{V}^{d 2}\right.\right. \\
\left.\left.-1.4617 \cdot 10^{-4} N_{V}^{d}+1.000146\right)\right]
\end{gathered}
$$

\subsection{Passing speed of vehicles on the bridges}

Generally speaking, three kinds of speed may be differentiated: instantaneous velocity (speed), at which a vehicle is moving at aiven moment when passing a given point of the road; travel speed, understood as the average speed, at which the vehicle crossed a segment of the road; and journey speed, understood as the effective speed accounting for the time when a vehicle does not move. When analysing the movement

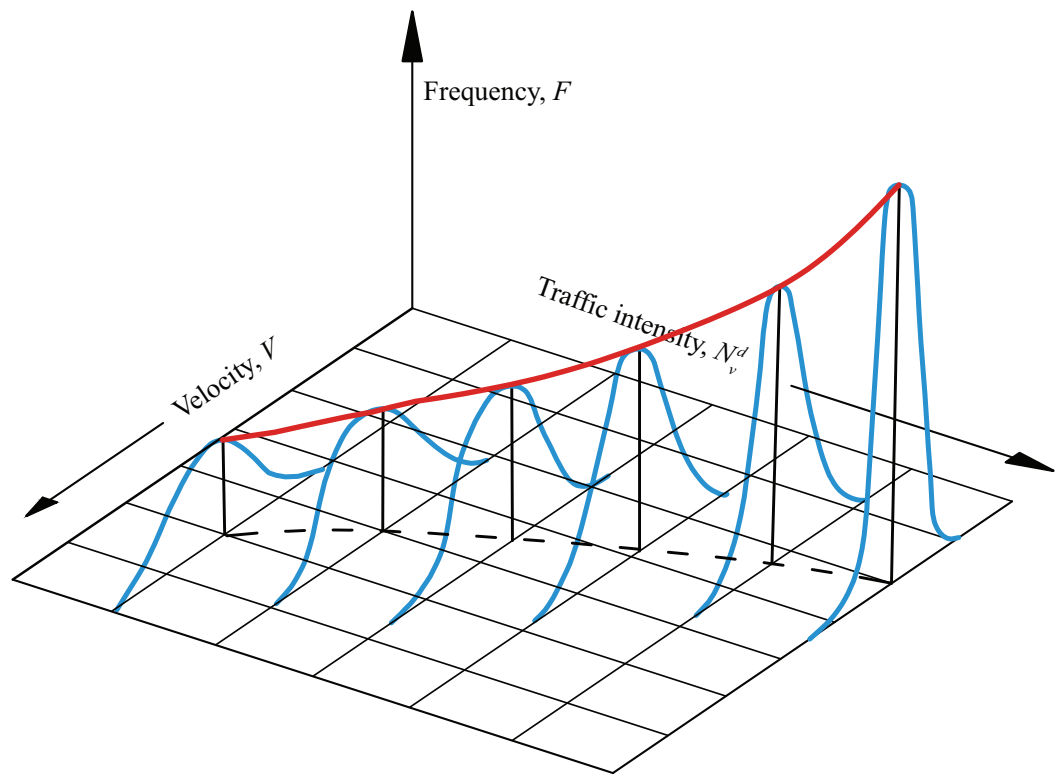

Figure 6. Speed distribution curves at various traffic volumes (Walker, 1974) 
of vehicles on a bridge, often a short segment of the road is considered. Only the instantaneous speed, at which the vehicles are travelling, is considered in this article. Its maximum value is limited by laws contained in the Highway Code and depends on the road segment, within which the analysed bridge is located. As shown in the previous works, the speed of vehicles can be described by a normal distribution. The American measurements (Moses, Goble, \& Pavia, 1975; Schilling, 1982; Walker, 1974) showed that for bridges located in lowland areas, the average of this distribution takes on the values slightly lower than the maximum permissible speed for heavy goods vehicles. Moreover, in accordance with Walker (1974), vehicle speed depends on the traffic volume. Analysing the course of the speed distribution curve at different traffic volumes, it was confirmed that the dispersion of speed decreases along with increasing traffic volume (Figure 6).

The phenomenon is explained considering the fact that in the case of high traffic volumes, the majority of vehicles are forced to travel at a speed similar to that at which the entire column of vehicles is moving (Zhang, \& Cai, 2012). In such cases, a uniform travel speed can be assumed for all vehicles moving along the bridge.

\subsection{Intervals between the vehicles}

Intervals between the vehicles can be analysed in time categories or in terms of distances between them. These intervals are generally measured between the given points (e.g. between the front of the analysed vehicle and the front of the vehicle preceding it). The measurements were carried out using a photocell installed on a special rack. The notion of a time gap, described as the time which passes from the time the end of the given vehicle crosses a given cross-section to the passing of the starting point by the next vehicle, is also used.

In order to determine the time intervals between vehicles for the national bridges, a field study was carried out. Measurements were carried out on a two-way, two-lane Bridge D, as well as on a one-way, three-lane Bridge $\mathrm{E}$. The time intervals between the vehicles (the front of the preceding vehicle and the front of the analysed vehicle) were registered over a day for each bridge using a special portable device applying pneumatic measuring method. This device enables counting of vehicle axles and the measurement of axle spacing, which is the basis for estimate of vehicle speed and its type. Figure 7 presents the obtained results of the intervals between the vehicles. In the case of Bridge E, measurements of traffic on this bridge at a daily traffic volume of $N_{V}^{d}=2976$ allow considering it is free-flowing. The green line vehicle 
traffic in columns. The blue line denotes traffic jam. In the event of heavy traffic, the distances between the vehicles will decrease significantly.

In Figure 8, the distribution of time intervals obtained, is given for a two-way, single carriageway Bridge $D$, for an average daily traffic volume of approximately 1000 heavy goods vehicles per hour, and for a oneway, three-lane Bridge E, at a traffic volume of approximately 185 heavy goods vehicles per hour. In $55-70 \%$ of cases, the time interval between the vehicles is shorter than the average interval.

Under certain conditions, the flow of vehicles can be considered a stochastic process (Frýba, 1999).

This takes place when:

- the location of any given vehicle is independent of other vehicles on the road, i.e. moving vehicles are treated as a set of random independent events;

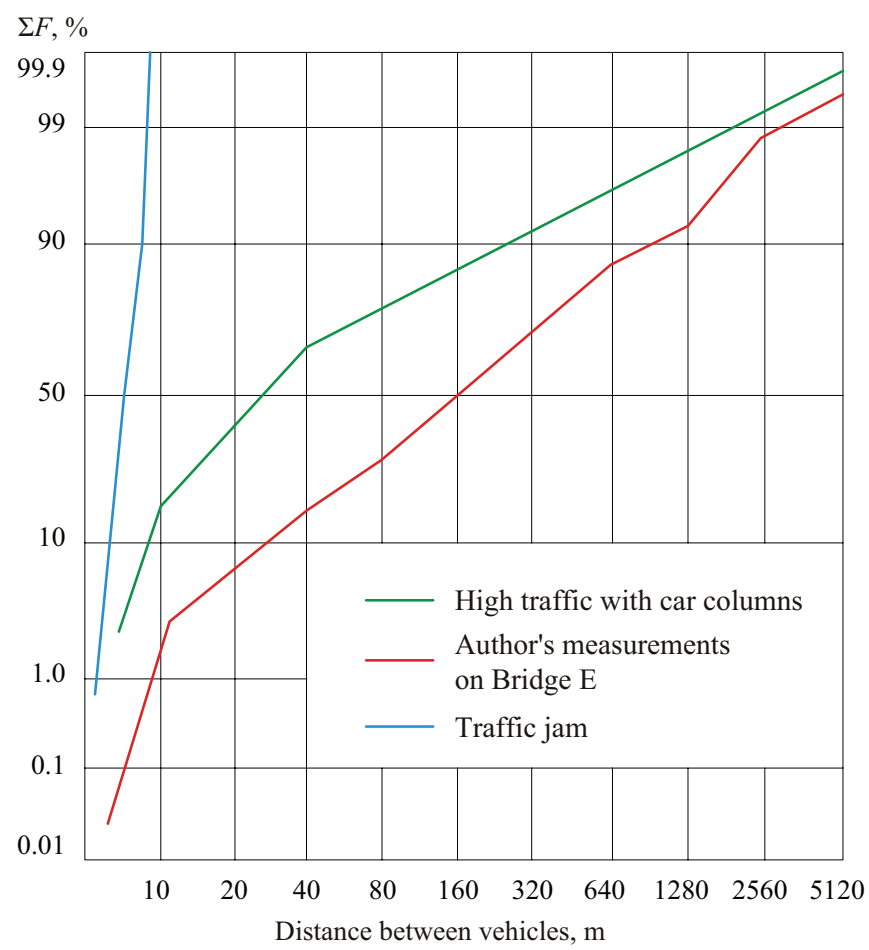

Figure 7. Distribution functions of the distance between vehicles according to measurements, at a daily traffic volume of $N_{V}^{d}=2976$ (red line). The green line refers to vehicle traffic in columns. The blue line denotes traffic jam (Pohl, 1977) 
- there is a constant probability that for segments of road of the same length, there is the same number of vehicles, i.e. the probability of the appearance of a vehicle on a given cross-section of a traffic lane in time interval $t$ depends only on the length of this interval.

In the case of fulfilling these assumptions, the distribution of the number of vehicles in individual time intervals can be described by the Poisson process (Iwankiewicz, \& Śniady, 1982). In this process, the number of crossings in a given time interval $t$ is a random variable of a Poisson distribution with parameter $\mu_{\mathrm{t}}$, and it can thus be written that the probability of the occurrence of $j$ events in time $t$. is equal to:

$$
P\left\{X^{t}=j\right\}=\frac{(\mu t)^{j}}{j !} e^{-\mu t},
$$

where $\mu$ is traffic velocity in vehicles per second.

Based on Eq. (3), the probability of occurrence of a time interval of a value higher or equal to the determined value $t$ can be written down as the probability of non-occurrence of a vehicle in a given time interval $t$ :

$$
P\left\{X^{t}=0\right\}=e^{-\mu t} \text {. }
$$

Having Eq. (4) noted down, we can, on its basis, derive relationships describing the distribution function of the distribution of time intervals between the vehicles as a distribution function of exponential distribution.

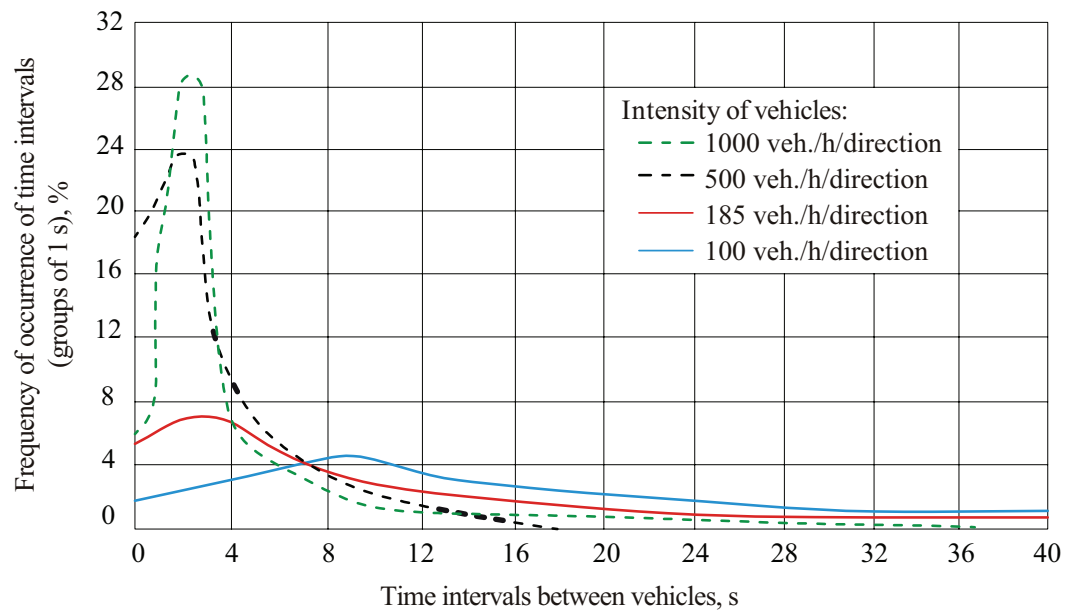

Figure 8. Distributions of time intervals for two- and four-lane road, as well as for a two-way two-lane bridge and one-way three-lane bridge according to the studies 


$$
F(\tau)=1-P\left\{X^{t}=0\right\},
$$

where $\tau$ is a time interval lesser than interval $t$.

The Poisson process is commonly applied in traffic engineering for modelling traffic streams. It is also used to determine maximum loads of structures under assumption that vehicles have identical dimensions and weight (Harman, et al. 1983; Moses, et al. 1975). Attempts to describe the results of field tests of road bridges in terms of this process have also been made (Croce, 2020; Wysokowski, 2018; Zhang, et al., 2017).

More precise studies showed that the distribution of intervals is similar enough to the Poisson distribution in the case of small traffic volumes (Harman, et al., 1983). Along with increasing volume, the share of shorter (1-2 s) intervals increases. As a result, in the case of higher traffic volumes, the observed values differ significantly from those theoretically calculated from Eq. (4).

The described differences can be explained as follows:

- the theoretical distribution covers the entire range of time interval variability, starting from zero. In reality, however, analysing traffic on a single lane, the intervals shorter than $0.5 \mathrm{~s}$ to $1 \mathrm{~s}$ may not occur. This leads to disagreement between the theoretical and actual distribution in the area of small-time intervals;

- in actual high-volume traffic conditions, intervals between the vehicles decrease more than can be expected from the traffic volume. Faster, lighter vehicles are grouped behind slower ones. In this case, the phenomenon of "grouping" occurs, observable especially in the case of two-way two-lane roads.

A comparison of time intervals obtained from own studies of Bridges $\mathrm{D}$ and E with the intervals established theoretically from the Poisson distribution for the analysed traffic volumes has been presented in Figure 9.

Analysing the results shown in Figure 9, relatively high agreement of the obtained time intervals with those determined theoretically can be observed, which is especially visible in the case of Bridge D. Somewhat greater differences, although practically without any greater significance, were noted in the case of Bridge E, which can be, to some degree, explained by the presence of traffic lights nearby, causing disturbances in even traffic volume.

This high compatibility stems from the fact that in the analysis, only intervals between heavy goods vehicles are analysed, the percentage of which in the total road traffic is merely $25-40 \%$. This leads to the situation that the intervals between heavy goods vehicles are greater as compared to the intervals between passenger vehicles due to their 
construction and specifics of movement (long braking distance), as well as the provisions of traffic laws.

In the case of time intervals between the vehicles greater than 4.0 seconds (considered when analysing heavy goods vehicle traffic), differences between the theoretical Poisson distribution and the empirical distribution do not practically exist. Assumption that the Poisson process models time intervals between reference fatigue vehicles moving on a single traffic lane adequately well in the entire range of their realized daily volumes, is presented in (Bruls, 1980; Hoogendoorn, et al., 2013; Krystek, 1970; Moses, et al., 1975).

In Figure 9, a relatively high compliance of the obtained intervals with the designated theoretical path is shown, particularly noticeable in the case of Bridge D. Greater differences with no less significance can be observed in the case of Bridge E, which can be explained by the presence of traffic lights that had an impact on the density of vehicle traffic during the tests. The high compatibility is explained by the fact that the analysis considered only the space between heavy goods vehicles, which constitute only about $25-40 \%$ of the total traffic. It means that even in conditions of heavy traffic, the distance between heavy goods vehicles will be large. The average noted distance between the vehicles in general traffic ranges from $100 \mathrm{~m}$ to $200 \mathrm{~m}$, whereas between heavy good vehicles - from $270 \mathrm{~m}$ to $1200 \mathrm{~m}$. Smaller average distances between the vehicles are observed only in traffic jams and traffic jams are expected to occur

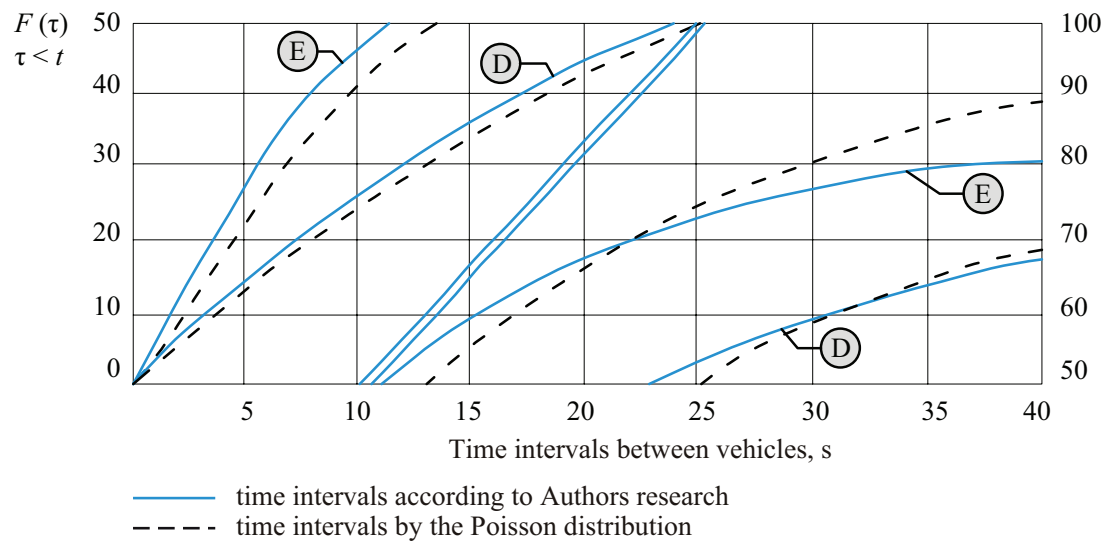

Figure 9. Comparison of the distribution functions of time intervals between vehicles obtained from studies on Bridges $D$ and $E$ with distribution functions derived theoretically from the Poisson distribution 
relatively infrequently. In addition, traffic jams comprise a separate on Fatigue of Steel problem. The problem of traffic jams should be accounted for only statistical deliberations, but not regarding the issues pertaining to the operational strength. Thus, it can be assumed that the distances between the vehicles are greater or equal to the lengths of the influence lines of these elements. It is also assumed with high probability that there is somewhat more than one heavy goods vehicle on the analysed segment of the traffic lane.

\section{Random model of vehicle traffic on the bridge}

Despite a large number of researches dedicated to operational strength published in many countries, none of them has specifically accounted for what could be a rather significant issue - the effect of overtaking of heavy goods vehicles on a bridge on the operational strength of its elements. In the present work, a random model describing the movement of vehicles on a bridge with any given number of traffic lanes at various volumes and passing speeds of heavy goods vehicles, is introduced. This particular random model could be used for simulation analysis of the operational strength of road bridges.

Figure 10 presents a bridge with the length of the analysed span $l$ and $k=n$ traffic lanes.

The probability that $j$-vehicles are present on the analysed bridge, described by the Poisson model, can be derived from Eq. (3).

The following assumptions are made:

- the speed of vehicles is discretionary, but constant within the bridge;

- vehicles do not change traffic lanes while on the bridge;

- the moving vehicles are treated as a collection of independent events;

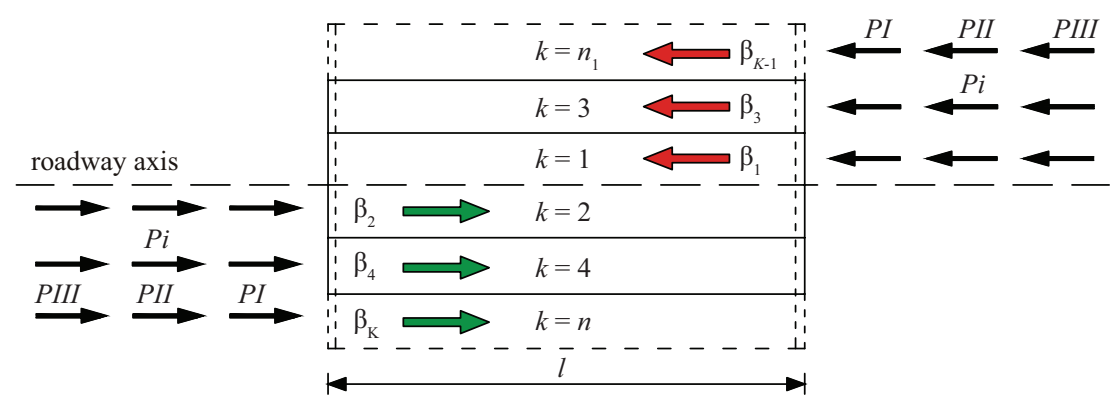

Figure 10. Diagram of the bridge with span length $l$ and $k=n$ traffic lanes 
- the probability of the occurrence of a vehicle on a given crosssection within time interval $t$ depends only on the length of this interval.

On the other hand, the probability that $j$-vehicles of the $i$-th type are on the $k$-th lane in time $t$ will be:

$$
P\left\{X_{i k}^{t}=j\right\}=\beta_{k} P_{i}\left[\frac{(\mu t)^{j}}{j !} e^{-\mu t}\right],
$$

where $P_{i}$ - probability of the occurrence of an $i$-th type vehicle; $\beta_{k}-$ probability of the occurrence of a vehicle on the $k$-th lane.

Let us take $Y_{i}^{t}=J$ to mean an event where $J$-vehicles of the $i$-th type appeared on the bridge. The probability that $j_{1}$ vehicles of the $i$-th type are found on $k=1$ lane, $j_{2}$ vehicles of the $i$-th type - on $k=2$ lane, as well as $j_{r}$ vehicles of the $i$-th type - on the $k=r$ lane can be expressed by Eq (8).

$$
\begin{aligned}
& P\left\{Y_{i}^{t}=J\right\}=\sum_{\substack{j_{1}, j_{2}, \ldots, j_{r}=0 \\
j_{1}+j_{2}+\ldots+j_{r}=J}}^{J} \\
& P\left\{X_{i 1}^{t}=j_{1}\right\} \cdot P\left\{X_{i 2}^{t}=j_{2}\right\} \cdot \ldots \cdot P\left\{X_{i r}^{t}=j_{r}\right\}
\end{aligned}
$$

Let us take $\Omega_{i_{1}, i_{2}, \ldots, i_{r}}^{t_{1 i^{\prime}, j}, \ldots}$ to signify an event when there are $j_{1}$ vehicles of the $i_{1}$ type, $j_{2}$ vehicles of the $i_{2}$ type, and $j_{r}$ vehicles of the $i_{r}$ type. The probability of occurrence of this event can be expressed by general Eq. (9).

$$
\begin{gathered}
\left.P\left\{\Omega_{i_{1}, j_{2}, \ldots, i_{r}}^{t_{j 1}, j_{2}, \ldots, j_{r}}=J\right\}=\sum_{\substack{j_{1}, j_{2}, \ldots, j_{r}=0 \\
j_{1}+j_{2}+\ldots+j_{r}=J}}^{J}{ }_{P\left\{Y_{i 1}^{t}=j_{1}\right\} \cdot P\left\{Y_{i 2}^{t}=j_{2}\right\} \ldots \cdot P\left\{Y_{i r}^{t}=j_{r}\right\}}\right\}
\end{gathered}
$$

where $i_{1} \neq i_{2} \neq \ldots \neq i_{r}$.

Then, dealing with the case of $i_{1} \neq i_{2} \neq \ldots \neq i_{n}$ direct use of Eq. (7) is considered.

Upon substituting Eq. (6) with Eq. (7), and in the case of various types of vehicles - Eq. (7) with Eq. (8), general formulas for calculation of the probability of occurrence of various types of configurations of events within the bridge are obtained, depending on the intensity of the inflow of vehicles as well as their time of moving across the bridge. These formulas are not written down here due to their excessively elaborate form. 
As mentioned in section 2.4, in practical applications we can only on Fatigue of Stee consider the case when there is a maximum of (no more than) one heavy goods vehicle on one traffic lane along the entire length of the bridge.

Accounting for this assumption, using the introduced Eq. (7) and Eq. (8), the conditional probability of subsequent events assumed to be $P^{\prime}\left\{X^{t}=j\right\}$ can be indicated under the assumption that an event that is their sum $\sum_{j=1}^{k} P^{\prime}\left\{X^{t}=j\right\}$ occurred (that is to say, 1 and $2 i \ldots j$-vehicles appeared on the bridge, depending on the number of traffic lanes $k, j=k$ ).

$$
\frac{P^{\prime}\left\{X^{t}=j\right\}=P\left\{X^{t}=j\right\}}{\sum_{j=1}^{k} P\left\{X^{t}=j\right\}}
$$

The value of the intensity of the inflow of vehicles $\mu$ onto the bridge over the course of a unit of time, under the assumption that the volume of vehicles per day in the cross-section of the bridge is $N_{V}^{d}$ and is more or less constant for 16 hours over the course of the day, can be derived from the practical relationship:

$$
\mu=\frac{N_{V}^{d}}{16 \cdot 60 \cdot 60}=\frac{N_{V}^{d}}{57.6 \cdot 10^{3}}
$$

At the same time, assuming that the length of the bridge or length of the dominant course of the influence line is $l$, and the speed of vehicles is $v$, as well as assuming that $t=l / v$, Eq. (3) takes on a more practical form when application to bridges is concerned:

$$
P\left\{X^{t}=j\right\}=\frac{(\mu l / v)^{j} j}{j_{1} \cdot e^{-\mu l / v}}
$$

\section{Computer simulation analysis of randomness of road traffic loads}

In order to develop a computer simulation, deterministic load sequences derived from traffic measurements to reflect real vehicle axle loads is used. The vehicles move on the theoretical bridge independently of each other, in the axes of individual lanes, above the theoretical influence lines of static values of the considered structural element of the steel bridge structure. In addition, the analysis considers a random model of traffic on the bridge, as well as the influence of the simultaneous passage of vehicles on the static quantities and the number of load cycles in the considered bridge girders. The general procedure for implementing the simulation 
method for indicating the spectra of strain ranges or the reaction of structural elements of bridges has been presented in Figure 11. Individual values of oscillograms of static values are calculated for cases when any given force "moving" over the influence line is found over its characteristic point, meaning the null value, maximum or minimum, as well as over the inflection point.

There is another exceptionally important issue in the process of assessment of the operational strength of a bridge. That is, it is necesary to deal with non-stationary strain spectra when counting the cycles of strain ranges for this type of assumed spectra. The problem appears when oscillograms of strains are transformed into histograms of strain ranges. Here, the well-known "Rain-Flow" method was applied. As a result of simulation numerical analysis, in addition to strain spectra, also

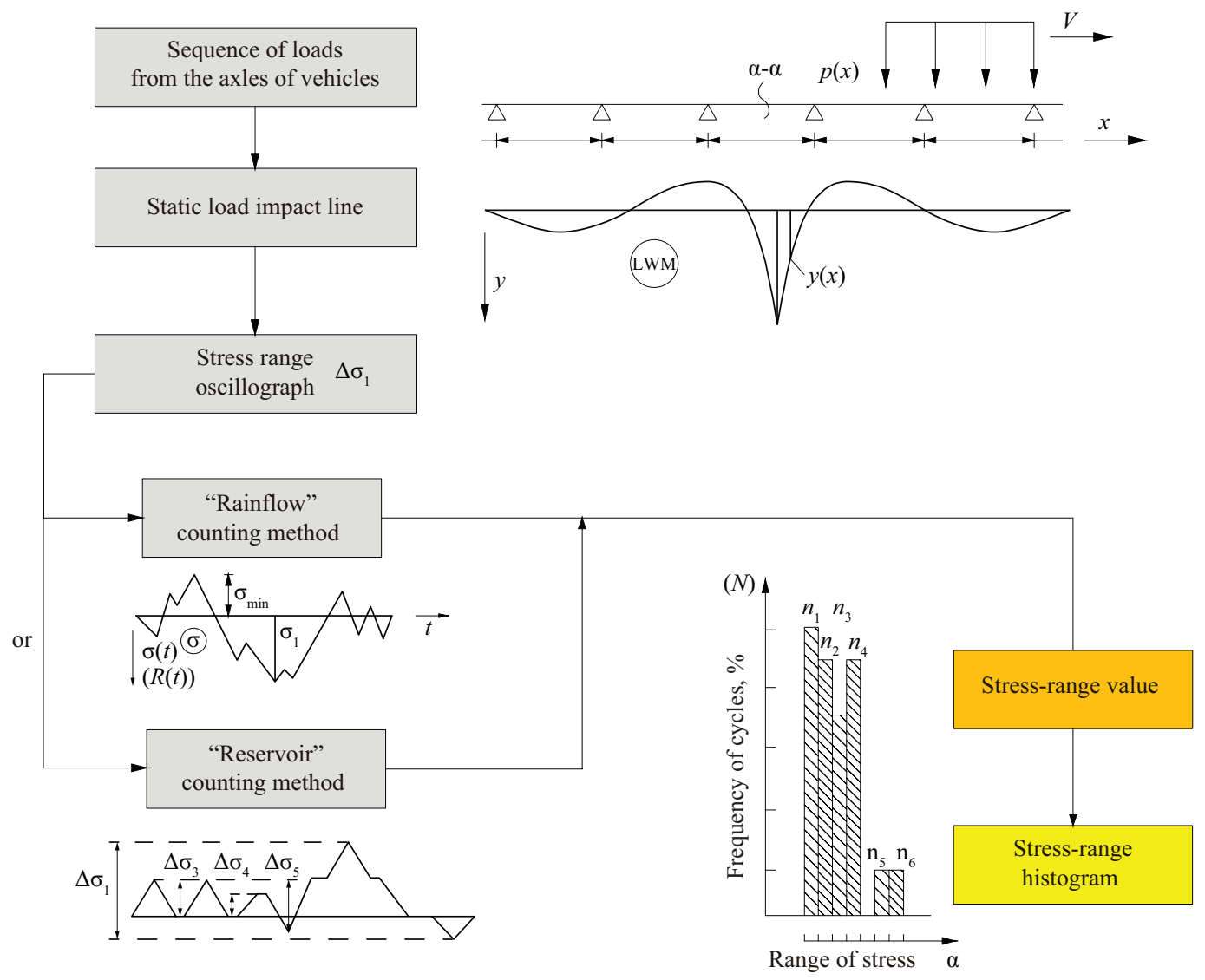

Figure 11. Outline of actions taken in the simulation method for indicating the spectra of strain ranges or reactions 
operational strength parameters for subsequent statistical diagrams of on Fatigue of Steel the main girders and elements of the main bridge deck were obtained (simply supported girders and multi-span continuous beams). These parameters for individual statistical diagrams are dependent on the lengths of the main girder spans, the daily traffic volume of vehicles and the speed of vehicles crossing the bridge.

\section{Influence of accounting for the randomness of road traffic loads on the value of operational strength parameters}

The analysis was carried out for various elements of two- and fourlane bridges in the case of a full range of volumes, from (heavy goods vehicles per day) $N_{V}^{d}=1$ to $N_{V}^{d}=7000$ (14 000) at various passing speeds of vehicles $V=8.3 \mathrm{~m} / \mathrm{s}(30 \mathrm{~km} / \mathrm{h}), 13.9 \mathrm{~m} / \mathrm{s}(50 \mathrm{~km} / \mathrm{h}), 19.4 \mathrm{~m} / \mathrm{s}$ (70 km/h), as well as $v=\infty$, without accounting for overtaking.

Figure 12 presents examples of strength diagrams of permissible stresses from standard loads $\sigma_{n \text {,acc }}$ for simply supported main girders

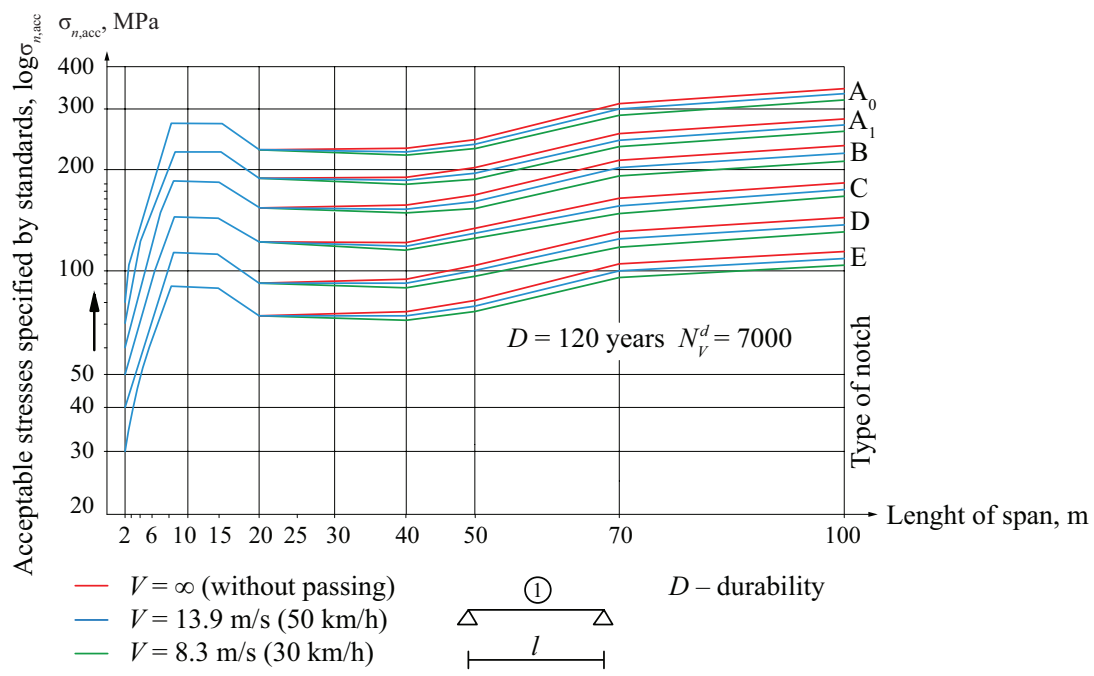

Figure 12. Graphs of values of permissible strains from standard loads $\sigma_{n, \text { acc }}$ for simply supported main girders of a two-lane steel bridge in the case of various notch coefficients, depending on the length of spans $(I)$ and various speeds of vehicles across the bridge 
of a two-lane bridge in the case of notch coefficients $\left(A_{0}-E\right)$, depending on the span length $l$ and at various vehicle speeds $v(v=\infty, 13.9 \mathrm{~m} / \mathrm{s}$, $8.3 \mathrm{~m} / \mathrm{s})$.

When analysing the graphs obtained as a result of computer simulation in Figure 12, it can be noticed that along with the increase in span length, the influence of the overtaking of vehicles on fatigue increases (Ye, et al., 2014). This results in the decline of values of permissible standard strains accounting for fatigue. In an effort to better illustrate the influence of the simultaneous moving of vehicles across a bridge (overlapping of loads from heavy goods vehicles found over the main girders of the bridge), the influence (percent) of accounting for the overtaking of cars on the durability of simply supported main girders of a two-lane bridge is seen as the value of a replacement equivalent number of cycles $N_{n}$ in the case of a constant speed of vehicles across the bridge $v=13.9 \mathrm{~m} / \mathrm{s}(50 \mathrm{~km} / \mathrm{h})$, depending on the volume of heavy good vehicles per day $N_{V}^{d}$. Similarly, the influence of accounting for the overtaking of vehicles on the strength of simply supported main girders at a constant traffic volume per day of $N_{V}^{d}=7000$ depending on the speed, at which they move across the bridge $v(8.3 \mathrm{~m} / \mathrm{s}, 13.9 \mathrm{~m} / \mathrm{s}$, $19.4 \mathrm{~m} / \mathrm{s}$ ), is presented in Figure 14 .

From the graphs presented in Figure 13, it can be clearly observed that along with the increase in the lengths of the bridge spans, the influence of the overtaking of vehicles on the fatigue of the main bridge girders increases. This can be explained by the overlapping of loads from

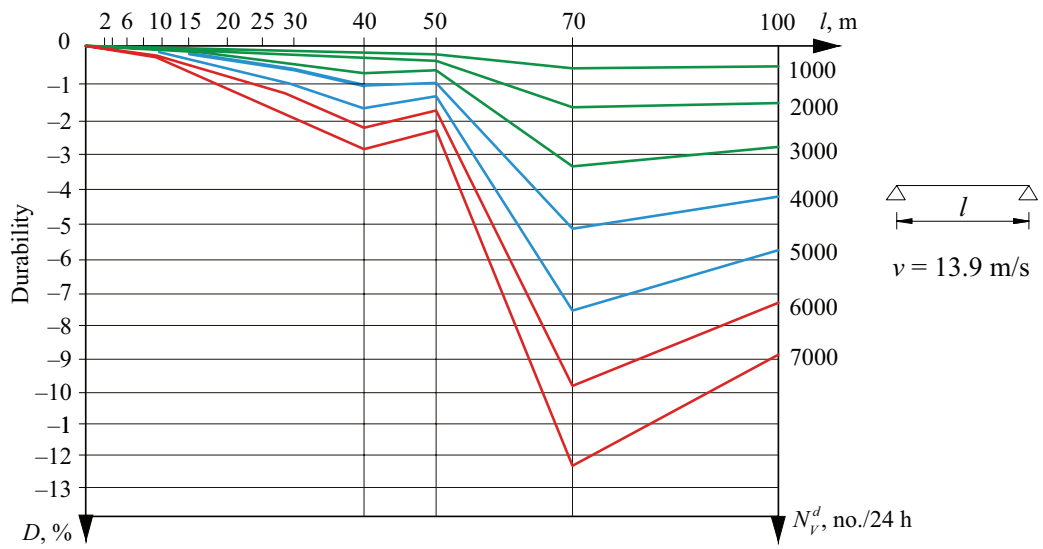

Figure 13. Influence of accounting for the passing of vehicles on the obtained operational strength (durability) of simply supported main girders of a twolane bridge in the case of speed $v=13.9 \mathrm{~m} / \mathrm{s}$ depending on the traffic volume per day $N_{V}^{d}$ 
heavy goods vehicles as they move simultaneously across the bridge. It results in the decreased durability of the main girder (in percent), as shown in Figure 12 and 13. It can additionally be noticed that the durability of bridge elements (in percent) falls along with the increase in the traffic volume on the bridge (overtaking of vehicles takes place more often).

As seen in Figure 13, at a constant traffic volume of $\left(N_{V}^{d}=7000\right)$ vehicles on the bridge, durability falls to a much greater degree at low speeds $(v=8.3 \mathrm{~m} / \mathrm{s}$ and $13.9 \mathrm{~m} / \mathrm{s})$ than at higher speeds $(19.4 \mathrm{~m} / \mathrm{s})$. This can be explained by more frequent overtaking of heavy goods vehicles on the bridge at low speeds than high ones. At low traffic speeds, the probability of simultaneous loading of a bridge with heavy goods vehicles increases, while at higher speeds of vehicles, the probability of simultaneous loading of the bridge is significantly smaller and decreases for bridges that are shorter in length.

The values in Figures 13 and 14 also depend on the dynamic factor, especially visible at a speed of $50 \mathrm{~km} / \mathrm{h}$. In Poland, as in many other countries, the dynamic factor of road loads is fully dependent on the bridge span. For the span above $70 \mathrm{~m}$, the factor is constant. The shape of graphs in Figure 13 is affected by the imposition of a load on the bridge growing with increasing span. These charts are compiled for one vehicle speed $v=13.9 \mathrm{~m} / \mathrm{s}$. Graphs in Figure 14 have been charted for the speeds most frequently encountered $(v=8.3 \mathrm{~m} / \mathrm{s}, 13.9 \mathrm{~m} / \mathrm{s}, 19.4 \mathrm{~m} / \mathrm{s})$ and presented as best reflecting the problem.

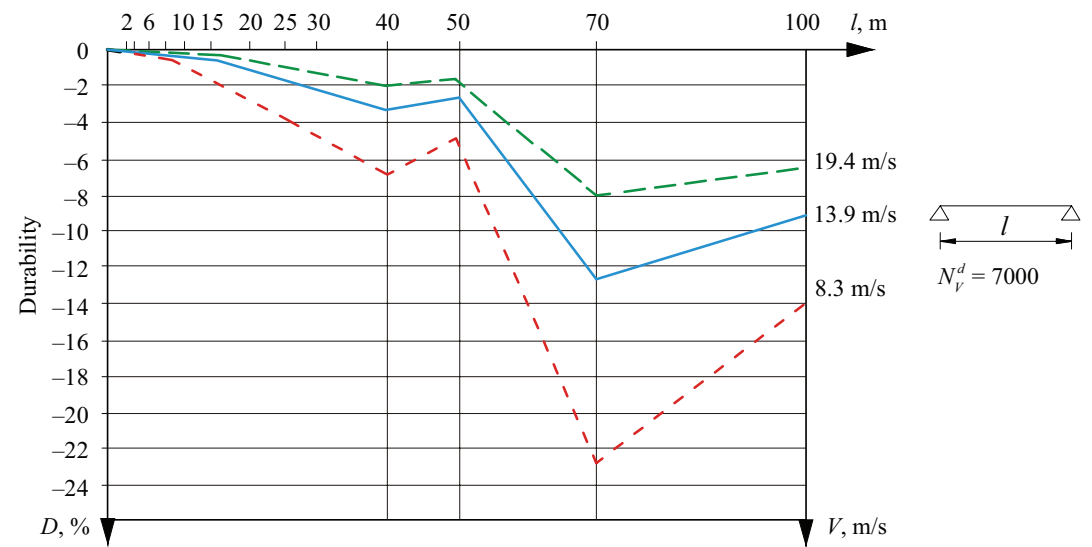

Figure 14. Influence of accounting for the overtaking of vehicles on the obtained strength (durability) of simply supported main girders of a twolane bridge in the case of traffic volume per day $N_{V}^{d}=7000$ depending on vehicles speed $v$ 


\section{Conclusions}

Randomness of road traffic influences the fatigue of steel bridge structures. It is connected with the overlapping of loads occurring with the simultaneous crossing of the bridge structure by the heavy goods vehicles over 3.5 tonnes.

The results of analyses are applicable only to the main girders of bridges. The following conclusions have been drawn:

1. The increase in fatigue parameters or the decrease in the durability of structural elements of road bridges depends on:

- the number of traffic lanes;

- the length of structural elements (e.g. main girder of the bridge);

- traffic volume, including mainly heavy goods vehicles;

- moving speeds of vehicles across the structure.

Conclusion No. 1 directly relates to the safety level of the steel bridge structures in service.

2. At large lengths of bridge spans, at high traffic volumes of heavy goods vehicles and at their high speeds, errors in the estimation of the amount of fatigue of the main girders of a road bridge can reach as much as $13 \%$. At the same time, for the reduced speed, the actual durability of the analysed bridge girders can be up to $23 \%$ lower than that calculated according to the common procedures, e.g. according to PN-EN 1993-1-9 standard.

3. There is no reason to analyse simultaneous crossing of a bridge by heavy goods vehicles in the case of short span structures, less than $10 \mathrm{~m}$.

Randomness of traffic on the bridge has a significant impact on their durability. Further analyses are needed in order to provide more accurate estimates considering various elements of the bridge structure. Randomness of traffic, non-axiality, division of traffic volume, speed of vehicles, distances between the vehicles have an effect on the magnitude of loads and thus stress in the structural elements of the bridge, especially the main girders. This, in turn, determines the fatigue life of the analysed elements of road bridges. In the Polish (PN-S-10030:1985, 1985) and European norms (PN-EN 1993-1-9, 2007), these issues are not comprehensively covered. The results of the present research may be useful in further studies, aimed at assessing the fatigue of steel road bridge structures with higher accuracy. 


\section{Acknowledgements}

The researcher would like to thank the Polish Ministry of Transport and Road and Bridge Research Institute for the possibility to conduct this research.

\section{REFERENCES}

Bruls, A. (1980). Comportement des ponts sous l'action du trafic routier. Association Belge pour l'Etude, l'Essai et l'Emploi des Matèriaux. Publication ABEM No. 444/1980. (in French)

Croce, P. (2019). Probabilistic Models for Vehicle Interactions in Fatigue Assessment of Bridges. Applied. Sciences, 9(24), 5338.

https://doi.org/10.3390/app9245338

Croce, P. (2020). Impact of Road Traffic Tendency in Europe on Fatigue Assessment of Bridges. Applied. Sciences, 10(4), 1389. https://doi.org/10.3390/app10041389

Frýba, L. (1999). Vibration of Solids and Structures Under Moving Loads. $3^{\text {rd }}$ ed. Thomas Telford, Prague-London, ISBN 0-7277-2741-9. https://doi.org/10.1680/vosasuml.35393

Guo, T., Frangopol, D. M., \& Chen, Y. (2012). Fatigue reliability assessment of steel bridge details integrating weigh-in-motion data and probabilistic finite element analysis. Computers \& Structures, 112-113, 245-257. https://doi.org/10.1016/j.compstruc.2012.09.002

Harman, D. J., Davenport, A. G., \& Wong, W. S. S. (1983). A Statistical Approach to Traffic Loading on Bridges. $4^{\text {th }}$ International Conference on Applications of Statics and Probability in Soil and Structural Engineering. Universita di Firenze, Pitagora Editrice.

Hoogendoorn, S. \& Knoop, V. (2013). Traffic flow theory and modelling. The Transport System and Transport Policy, 125-159.

Iwankiewicz, R., \& Śniady, P. (1982). Dynamic Response of a Beam to Random Train of Moving Forces. Second Conference on Safety of Bridge Structures. Wrocław University of Technology.

Jacquemoud, J. (1980). Analyse du comportement a la fatique des ponts-routes. Thèse no 389. Ecole polytechnique fèdèrale, Lausanne. (in French)

Krystek, R. (1970). The impact of the width and density of car traffic on one-way streets on the size of the border gap and changes in probability distributions. PhD thesis. Gdansk University of Technology.

Kwon, K., \& Frangopol, D. M. (2010). Bridge fatigue reliability assessment using probability density functions of equivalent stress range based on field monitoring data. International Journal of Fatigue, 32(8), 1221-1232.

https://doi.org/10.1016/j.ijfatigue.2010.01.002

Liu, Y., Xiao, X., Lu, N., \& Deng, Y. (2016). Fatigue Reliability Assessment of Orthotropic Bridge Decks under Stochastic Truck Loading. Shock and Vibration, 2016, 4712593. https://doi.org/10.1155/2016/4712593 
Moses, F., Goble, G., \& Pavia, A. (1975). Truck Loading Model for Bridge Fatigue. Speciality Conference on Metal Bridges. St. Louis 1974. Proceedings of the ASCE 1.

O’Brien, E. J., \& Enright, B. (2011). Modeling same-direction two-lane traffic for bridge loading. Structural Safety, 33(4-5), 296-304. https://doi.org/10.1016/j.strusafe.2011.04.004

Pfeifer, M. R. (1982). Verkehrslasten und Beanspruchungen von Strassenbrücken. IABSE Proceedings, 37, Lausanne. (in German)

PN-S-10030:1985 (1985). Bridges-Loads. Polish Committee for Standardization.

PN-EN 1993-1-9 (2007). Eurokod 3. Design of steel structures. Part 1-9: Fatigue.

Pohl, S. (1977). Strassenverkehrsdaten als Grundlage fur Beanspruchungskollektive von Strassenbrucken. Die Strasse, 17(4), 150-154. (in German)

Schilling, Ch. G. (1982). Lateral - Distribution Factors for Fatigue Design. Journal of the Structural Division, 108(ST-9), 2015-2033.

Song, YS., \& Ding, YL. (2013). Fatigue monitoring and analysis of orthotropic steel deck considering traffic volume and ambient temperature. Science China Technological Sciences, 56, 1758-1766. https://doi.org/10.1007/s11431-013-5235-0

Walker, W. H. (1974). Loading Histories. Speciality Conference on Metal Bridges. St Louis, Missouri, 1974.

Wenzel, H., \& Veit-Egerer, R. (2009). Measurement-based traffic loading assessment of steel bridges - a basis for performance prediction. Structure and Infrastructure Engineering, 7(4), 261-273. https://doi.org/10.1080/15732470802586428

Wysokowski, A. (2001). Durability of steel bridges as a function of fatigue and corrosion phenomena. Roads and Bridges Research Institute. Studies and Materials, no. 53. Warsaw. Available from: https://ibdim.edu.pl/index.php/ en/publications/serie-wydawnicze/225-seria-s-studia-i-materialy

Wysokowski, A. (2018). Research on changes in properties of steel from the old road bridge. Journal of Constructional Steel Research, 147, 360-366. https://doi.org/10.1016/j.jcsr.2018.02.014

Yan, J., Deng, L., \& He, W. (2016). Evaluation of existing prestressed concrete bridges considering the randomness of live load distribution factor due to random vehicle loading position. Advances in Structural Engineering, 20(5), 737-746. https://doi.org/10.1177/1369433216664350

Ye, X. W., Su, Y. H., \& Han, J. P. (2014). A State-of-the-Art Review on Fatigue Life Assessment of Steel Bridges. Mathematical Problems in Engineering, 2014, 956473. https://doi.org/10.1155/2014/956473

Zhang, W., \& Cai, C. S. (2012). Fatigue Reliability Assessment for Existing Bridges Considering Vehicle Speed and Road Surface Conditions. Journal of Bridge Engineering, 17(3). https://doi.org/10.1061/(ASCE)BE.1943-5592.0000272

Zhang, W., Wu, M., \& Zhu, J. (2017). Evaluation of vehicular dynamic effects for the life cycle fatigue design of short-span bridges. Steel Construction, 10(1), 37-46. https://doi.org/10.1002/stco.201710008 